\title{
Prediksi Kecepatan Angin Menggunakan Adaptive Neuro Fuzzy (ANFIS) dan Radial Basis Function Neural Network (RBFNN)
}

\author{
Nerfita Nikentari ${ }^{\# 1}$, Martaleli Bettiza ${ }^{* 2}$, Helen Sasty Pratiwi ${ }^{\# 3}$ \\ \# Jurusan Teknik Informatika, Universitas Maritim Raja Ali Haji dan Universitas Tanjungpura \\ Jl. Polteknik Senggarang No.1 \\ ${ }^{1}$ nerfita.nikentari@umrah.ac.id \\ ${ }^{3}$ helensastypratiwi@informatics.untan.ac.id \\ *Universitas Universitas Maritim Raja Ali Haji \\ Jl. Polteknik Senggarang No.1 \\ ${ }^{2}$ mbettiza@umrah.ac.id
}

\begin{abstract}
Abstrak - Angin sebagai salah satu fenomena alam yang mempengaruhi berbagai aspek dalam kehidupan manusia baik pengaruh positif maupun negatif. Aspek ini berperan besar dalam ekonomi, pariwisata, pembangunan, transportasi maupun perdagangan masyarakat. Data angin dalam hal ini kecepatan angin belum dapat diketahui secara pasti nilainya oleh karena itu perlu adanya prediksi. Adaptive Neuro Fuzzy Inference System (ANFIS) dan Radial Basis Function Neural Networkc(RBFNN) adalah algoritma yang dapat digunakan untuk prediksi data. Penelitian ini menggunakan ANFIS dan RBFNN untuk memprediksi kecepatan angin. Data prediksi yang digunakan dalam penelitian ini adalah data time series. Data kecepatan angin diperoleh dari BMKG (Badan Meteorologi Klimatogi dan Geofisika) Tanjungpinang, Kepualuan Riau. Hasil prediksi dengan kedua metode ini dibandingan dengan data asli untuk mengetahui metode mana yang lebih akurat dalam prediksi data. Hasil pengujian menggunakan kedua algoritma memperlihatkan akurasi terbaik (paling mendekati data asli/target) diperoleh oleh RBFNN yaitu dengan nilai RMSE adalah 0,1766 dan hasil RMSE ANFIS adalah 1,1456.
\end{abstract}

Kata kunci - prediksi, kecepatan angin, ANFIS, RBFNN

\section{Pendahuluan}

Angin merupakan salah satu fenomena alam yang tidak dapat dipisahkan dari kehidupan manusia. Angin memegang peranan penting dalam berbagai aspek kehidupan manusia. Peranan penting angin antara lain dalam bidang transportasi laut yaitu pelayaran, transportasi udara dimana angin sebagai salah satu unsur meteorologi penting dalam proses lepas landas (take off), penerbangan, dan mendarat (landing)[1], sumber energi alternatif terbarukan yaitu sebagai salah satu sumber pembangkit tenaga listrik untuk mengatasi masalah keterbatasan sumber daya energi[2]. Fenomena alam ini juga memberikan dampak negatif yang dapat merugikan dan menimbulkan masalah bagi manusia ketika menghasilkan kecepatan dan kekuatan melebihi normal[3].

Kecepatan angin tidak dapat dipastikan karena berubah-ubah setiap waktu. Prediksi kecepatan angin dapat digunakan untuk mencegah dampak negatif dari angin dan mengoptimasi peranan positif angin dalam kehidupan sehari-hari manusia.

Jaringan syaraf tiruan (JST) merupakan salah satu metode dalam ilmu komputer sering digunakan untuk prediksi. Perbagai penelitian telah dilakukan terkait prediksi dengan menggunakan ANFSIS dan RBFNN. Dewi dan Himawati melakukan prediksi tingkat pengangguran menggunakan Adaptive Neuro Fuzzy Inference System (ANFIS). Penelitian ini mengimplementasikan ANFIS dengan inferensi fuzzy Sugeno Orde-Satu, fungsi aktivasiyang digunakan adalah sigmoid biner dan menggunakan fungsi keanggotaan generalized bell. Dari 70 data latih nilai learning rate 0,6 memberikan hasil paling optimal yaitu memberikan nilai RMSE 1,274 dan akurasi prediksi adalah sebesar 93,33\% [4].

ANFIS untuk memprediksi diabetes dan kanker dipaparkan dalam penelitian Kalaiselvi dan Nasira. Hasil percobaan yang menggunakan 768 data dengan atribut jumlah kali kehamilan, tingat glukosa, tekanan darah, ruam dan ketebalan kulit, usia dan silsilah diabetes, didapat hasil prediksi dengan tingkat akurasi sebesar $80 \%$ [5].

Altaher dalam penelitiannya menggunakan metode ANFIS dengan clustering menggunakan Fuzzy C-Means dalam mengklasifikasi malware pada sistem operasi Android. Proses dalam penelitian ini terdiri dari 3 fase yaitu feature extracted dari file Android APK, clustering malware menjadi 2 kelompok yaitu malware and goodware, dan yang terkahir ANFIS diimplementasikan 
untuk mengklasifikasikan malware dan goodware. Hasil klasifikasi menunjukkan tingkat akurasi adalah 93\% [6].

Svalina dan Simunovic mengembangkan model untuk memprediksi harga penutupan saham di Zagreb Stock Exchange Crobex untuk 5 hari kedepan menggunakan ANFIS. Data input dan output merupakan data historikal dari 4 November 2010 hingga 24 Januari 2012. Penelitian ini menampilkan estimasi secara kualitatif dan kuantitatifyang menunjukkan bahwa ANFIS dapat digunakan untuk prediksi harga saham penutupan[7].

Rout dan Dash menggunakan RBFNN dan algoritma pembelajaran Lavenberg-Marquardt untuk memprediksi harga pertukaran mata uang asing. RBFNN dan algoritma pembelajaran Lavemberg-Marquardt diintegrasikan sehingga menghasilkan hybrid model sehingga dapat digunakan untuk memprediksi. Model Hybrid ini dinamakan Functional Link Radial Basis Function (FLRBF). Data yang digunakan adalah mata uang dollar Amerika terhadap 4 mata uang lainnya yaitu Euro, Rupee, dolar Canada dan dolar Australia dari periode January 2004 hingga January 2014. Hasil prediksi dari FLRBF dibandingkan dengan liner, nonlinear dan hybrid neural network. Hasil perbadingan menunjukkan FLRBF lebih baik dari semua metode yang dibandingan. Akurasi prediksi diketahui dengan menggunakan indikator akurasi yaitu Mean Absolute Error (MAE), Root Mean Squared Error (RMSE) dan Mean Absolute Percentage Error (MAPE)[8].

Santosa dkk melakukan penelitian dengan judul Model Prediksi Penyakit Ginjal Kronik Menggunakan Radial Basis Function. Penelitian ini menggunkan struktur 24-2-2, yaitu 24 input layer, 2 node pada hidden layer, dan 2 node pada output layer, hasil akurasi prediksi dari hasil pengujian adalah 93.75\%[9]. RBFNN digunakan oleh Chang untuk memprediksi beban listrik jangka pendek. Jumlah node input yang juga merepresentasikan varibel input pada penelitian ini ada 4 yaitu data 20 menit sebelum, data 10 menit sebelum, data saat ini dan data suhu. Jumlah data yang digunakan adalah 740 data. Metode yang digunakan untuk menentukan tingkat akurasi prediksi adalah maximum absolute percentage error dan MAPE[10].

Penelitan ini bertujuan untuk membandingkan metode ANIFS dan RBFNN untuk memprediksi kecepatan angin dengan tujuan untuk mengetahui metode yang memiliki tingkat akurasi paling baik, yang dalam hal ini adalah hasil akurasi data hasil prediksi paling mendekati data asli.

\section{METODELOGI}

\section{A. Data}

Data yang digunakan dalam penelitian ini adalah data rata-rata kecepatan angin tahun 2017 pada bulan JanuariOktober di Pulau Bintan berjumlah 296 data. Data ini diperoleh dari BMKG (Badan Meteorologi Klimatogi dan Geofisika) Tanjungpinang dalam bentuk time series. Untuk melakukan prediksi menggunakan metode ANFIS, data rata-rata kecepatan angin dibagi menjadi 2 untuk data pelatihan (training) dan data pengujian (testing). Pembagian data yang digunakan adalah $80 \%$ untuk pelatihan dan $20 \%$ digunakan untuk pengujian.

Proses training digunakan sebagai proses pembelajaran dan untuk mencari parameter premis yang menghasilkan error terkecil. Skala Beaufort merupakan skala untuk mengukur kecapatan angin yang digunakan dalam penelitian ini. Skala ini mengukur kecepatan angin dengan menggambarkan pengaruhnya pada gelombang air laut. Skala Beaufort digunakan pada proses ANFIS yaitu untuk proses klasifikasi data menggunakan Fuzzy C-Means.

Tahun 1947 WMO (World Meteorological Organization) atau Organisasi Meteorologi Dunia menetapkan standar baku skala Beaufort seperti terlihat pada tabel I [11].

TABEL I

SKALA BEAFOURT

\begin{tabular}{|c|c|c|c|}
\hline $\begin{array}{l}\text { Number } \\
\text { of Scale }\end{array}$ & \multicolumn{2}{|c|}{ Description } & Wind Speed \\
\hline 0 & Calm & \multirow{6}{*}{$\begin{array}{l}\text { Light } \\
\text { Winds }\end{array}$} & $<1 \mathrm{knot}$ \\
\hline 1 & Light Air & & $1-3$ knots \\
\hline 2 & Light Breeze & & 4-6 knots \\
\hline 3 & $\begin{array}{l}\text { Gentle } \\
\text { Breeze }\end{array}$ & & $7-10$ knots \\
\hline 4 & $\begin{array}{c}\text { Moderate } \\
\text { Breeze }\end{array}$ & & $11-16$ knots \\
\hline 5 & Fresh Breeze & & $17-21$ knots \\
\hline 6 & $\begin{array}{l}\text { Strong } \\
\text { Breeze }\end{array}$ & \multirow{2}{*}{ High Winds } & $22-27$ knots \\
\hline 7 & Near Gale & & $28-33$ knots \\
\hline 8 & Gale & \multirow{2}{*}{ Gale-force } & $34-40$ knots \\
\hline 9 & Strong Gale & & $41-47$ knots \\
\hline 10 & Storm & \multirow[b]{2}{*}{ Storm-force } & $48-55$ knots \\
\hline 11 & $\begin{array}{l}\text { Violent } \\
\text { Storm }\end{array}$ & & $56-63$ knots \\
\hline 12 & $\begin{array}{c}\text { Hurricane } \\
\text { Force }\end{array}$ & $\begin{array}{c}\text { Hurricane- } \\
\text { force }\end{array}$ & $\geq 63$ knots \\
\hline
\end{tabular}

\section{B. Root Mean Squared Error (RMSE)}

Teknik evaluasi hasil peramalan yang digunakan dalam penelitian ini adalah RMSE. RMSE telah digunakan sebagai matrik statistik standar untuk mengukur keakuratan kinerja berbagai model[12]. Evaluasi untuk mengetahui tingkat perbedaan antara hasil peramalan dengan nilai data yang sebenarnya terjadi.

$$
\text { RMSE }=\sqrt{\frac{\sum_{t-1}^{n}\left(f_{t}-f\right)^{2}}{n}}
$$

Dimana: 
$f t=$ output target;

$f=$ output jaringan;

$n=$ jumlah data.

\section{Flowchart Proses Prediksi}

Secara umum berikut merupakan proses prediksi yang dilakukan oleh ANFIS dan RBF.

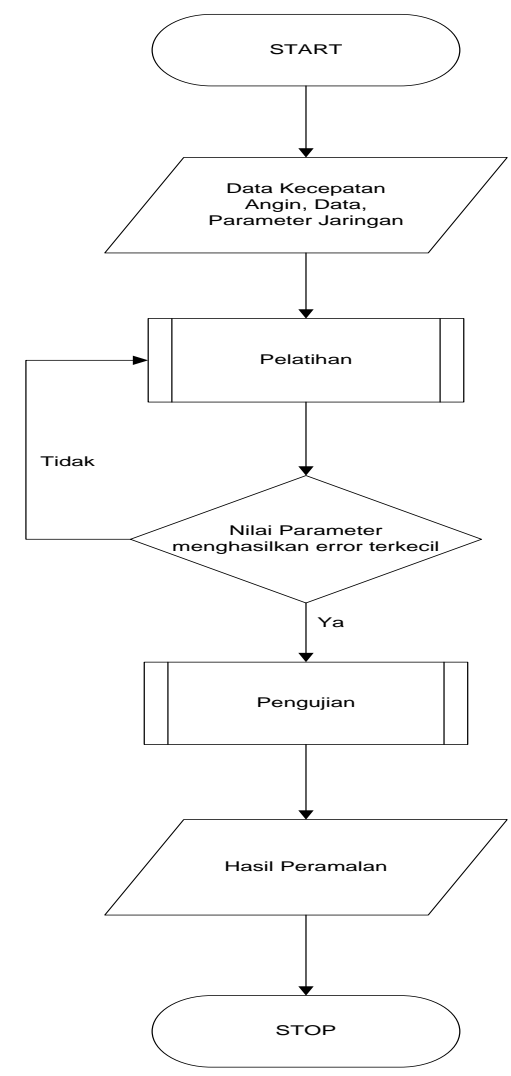

Gambar. 2 Flowchart Prediksi Kecepatan Angin

\section{Arsitektur ANFIS dan RBFNN}

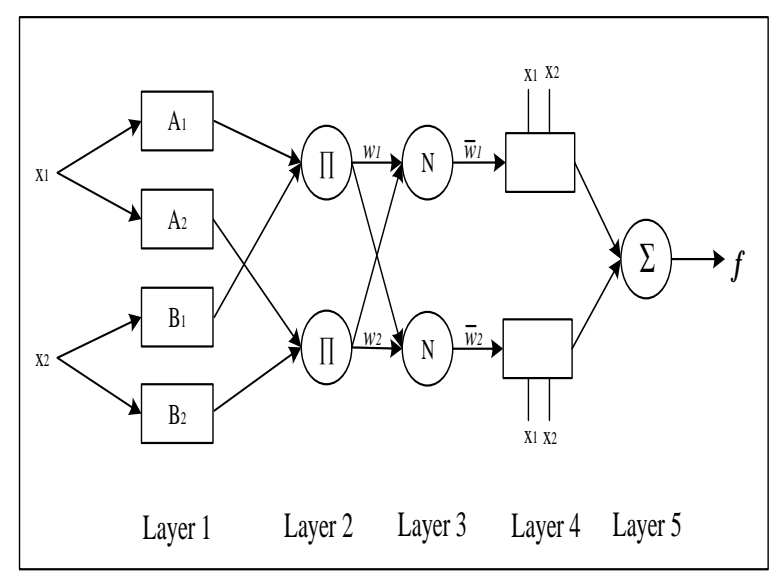

Gambar. 2 Arsitektur ANFIS Prediksi Kecepatan Angin

Arsitektur dari ANFIS dapat dilihat pada gambar 2, dimana parameter awal ANFIS dengan clustering menggunakan metode Fuzzy C-Means adalah sebagai berikut :

$\begin{array}{ll}\text { Jumlah variabel input } & : 4 \\ \text { Jumlah } \text { cluster } & : 2 \\ \text { Pangkat (w) } & : 2 \\ \text { Maksimum iterasi (maxIter) } & : 10 \\ \text { Error terkecil } & : 10^{-3}\end{array}$

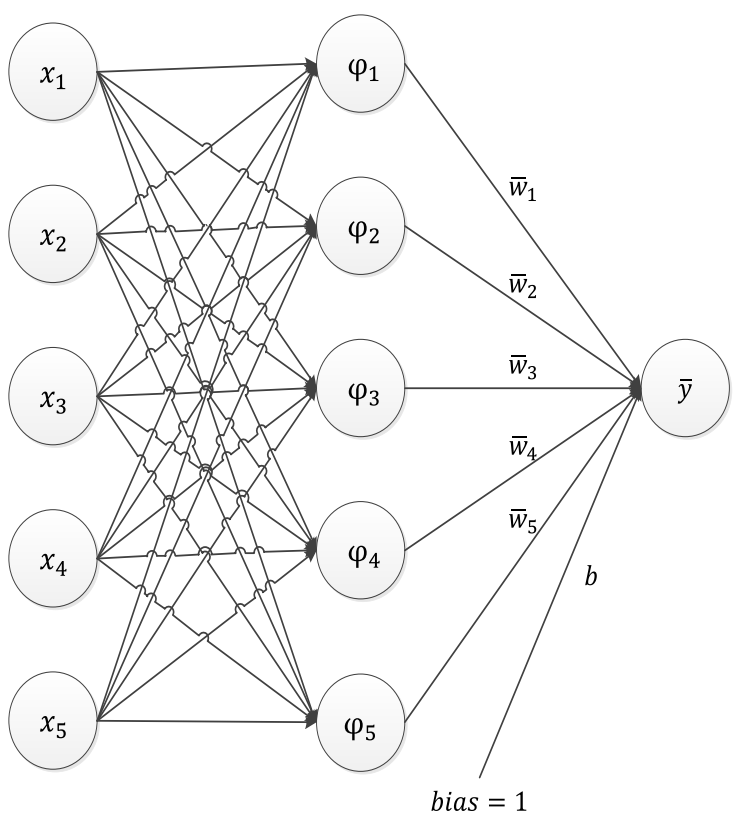

Gambar. 3 Arsitektur RBFNN Prediksi Kecepatan Angin

Arsitektur dari jaringan syaraf radial basis function dapat dilihat pada gambar 4. Pada RBFNN untuk menentukan pusat kluster dilakukan secara random, dengan fungsi aktivasi yang digunakan adalah Gaussian, data parameter yang digunakan adalah sebagai berikut :

Jumlah variabel input $: 5$

Jumlah center $\quad: 5$

Nilai spread $\quad: 0,3779$

\section{HASIL DAN PEMBAHAAN}

\section{A. ANFIS}

Pada ANFIS dilakukan 4 model pelatihan dan pengujian. Empat model tersebut adalah:

a. Pelatihan dan pengujian dengan menggunakan jumlah masukan 1 variabel input berupa data ratarata kecepatan angin pada hari sekarang (xt) dan data rata-rata kecepatan angin pada hari selanjutnya $(\mathrm{xt}+1)$ untuk variabel output.

b. Pelatihan dan pengujian dengan menggunakan jumlah masukan 2 variabel input berupa data ratarata kecepatan angin pada hari sebelumnya (xt-1), data rata-rata kecepatan pada angin hari sekarang (xt) dan data rata-rata kecepatan angin pada hari selanjutnya $(\mathrm{xt}+1)$ untuk variabel output.

c. Pelatihan dan pengujian dengan menggunakan jumlah masukan 3 variabel input berupa data ratarata kecepatan angin pada hari sebelumnya (xt-1, xt2), data rata-rata kecepatan pada angin hari sekarang 
(xt) dan data rata-rata kecepatan angin pada hari selanjutnya $(\mathrm{xt}+1)$ untuk variabel output.

d. Pelatihan dan pengujian dengan menggunakan jumlah masukan 4 variabel input berupa data ratarata kecepatan angin pada hari sebelumnya (xt-1, xt2, xt-3), data rata-rata kecepatan pada angin hari sekarang (xt) dan data rata-rata kecepatan angin pada hari selanjutnya $(\mathrm{xt}+1)$ untuk variabel output.

Keempat model data set dilatih dan diuji lalu dibandingkan untuk menemukan model arsitektur ANFIS terbaik yang memberikan hasil prediksi yang optimum. Prediksi rata-rata kecepatan angin diambil dari hasil pengujian yang memberikan rata-rata kesalahan terkecil yang diukur menggunakan RMSE. Grafik perbandingan RMSE pada proses pelatihan dan pengujian dari masingmasing model data set dapat dilihat pada gambar 4 .

\section{RMSE PADA DATA SET MODEL $1,2,3$ \& 4}

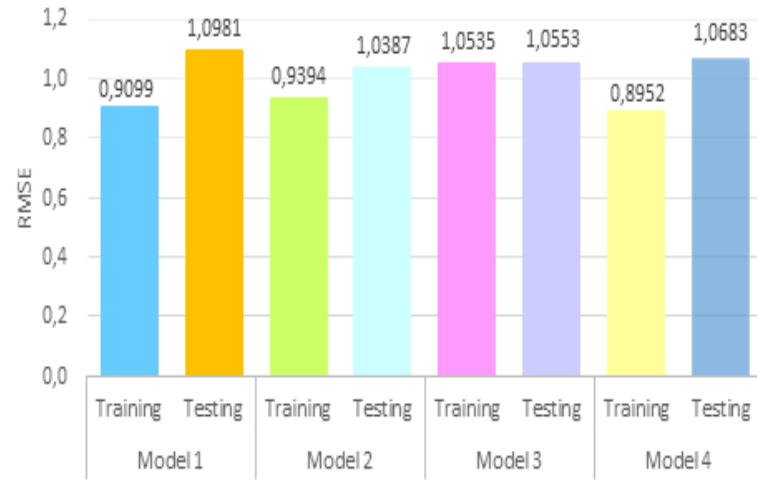

Gambar. 4 Grafik perbandingan RMSE pada data latih dan uji pada semua model data set

Persentase akurasi prediksi pada model 1, 2,3 \& 4

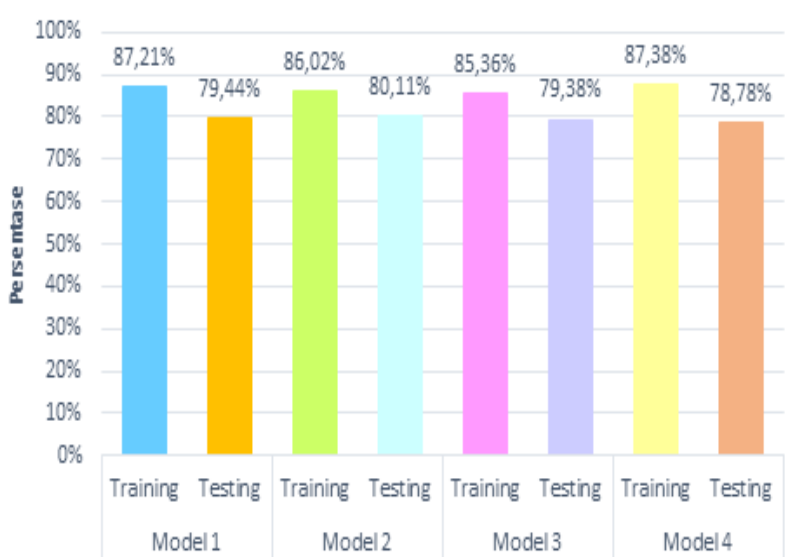

Gambar 5. Grafik perbandingan persentase akurasi prediksi pada data latih dan uji

Gambar 4 dan gambar 5 menunjukkan model yang terbaik adalah model ke 4 ditunjukkan dengan nilai RMSE paling kecil dan angka akurasi paling tinggi dibandingkan dengan model lainnnya. Data hasil prediksi menggunakan model ke 4 dapat dilihat pada tabel 2.
TABEL II

HASIL PENGUJIAN PADA DATA SET MODEL KE-4

\begin{tabular}{|c|c|c|c|c|c|c|}
\hline \multirow{2}{*}{ No } & \multicolumn{4}{|c|}{ Input } & \multicolumn{3}{c|}{ Output } \\
\cline { 2 - 7 } & $\begin{array}{c}\text { xt- } \\
3\end{array}$ & $\begin{array}{c}\text { xt- } \\
2\end{array}$ & $\begin{array}{c}\text { xt- } \\
1\end{array}$ & xt & $\begin{array}{c}\text { Target } \\
(x t+1)\end{array}$ & Testing \\
\hline 1 & 5 & 5 & 5 & 5 & 6 & 5.65 \\
\hline 2 & 5 & 5 & 5 & 6 & 5 & 5.58 \\
\hline 3 & 5 & 5 & 6 & 5 & 7 & 5.51 \\
\hline$\ldots$ & $\cdots$ & $\cdots$ & $\cdots$ & $\cdots$ & $\cdots$ & $\cdots$ \\
\hline$\cdots$ & $\cdots$ & $\cdots$ & $\cdots$ & $\cdots$ & $\ldots$ & $\ldots$ \\
\hline$\ldots$ & $\cdots$ & $\cdots$ & $\cdots$ & $\cdots$ & $\cdots$ & $\cdots$ \\
\hline 52 & 6 & 4 & 4 & 4 & 5 & 6.16 \\
\hline 53 & 4 & 4 & 4 & 5 & 8 & 6.26 \\
\hline 54 & 4 & 4 & 5 & 8 & 4 & 6.02 \\
\hline
\end{tabular}

Hasil pengujian dibandingkan dengan data asli (target) dapat dilihat pada gambar 6. Tebel II dan gambar 6 menunjukkan data hasil pengujian mendekati nilai dari data target

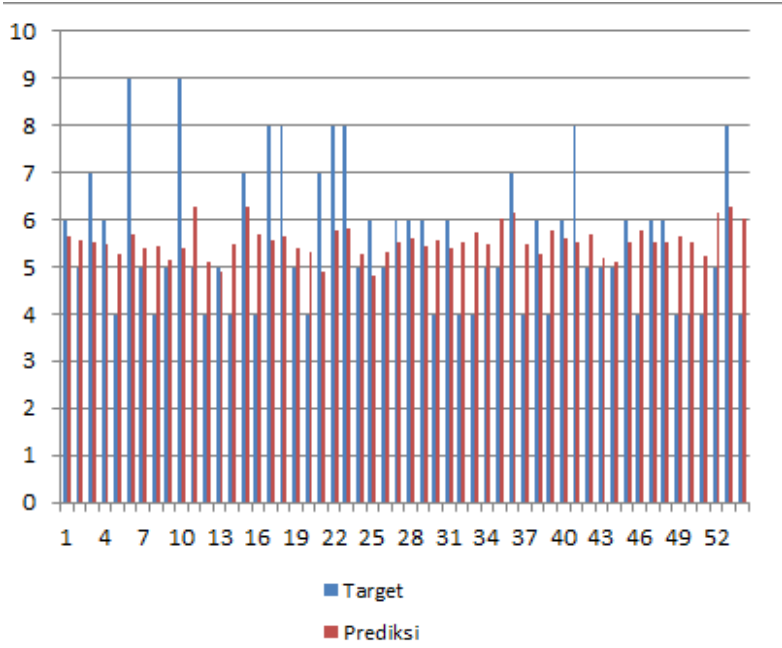

Gambar 6. Grafik perbandingan persentase akurasi prediksi pada data latih dan uji

\section{B. RBFNN}

Hasil pelatihan dan pengujian kecepatan angin dengan menggunakan RBFNN menggunakan skema 5-5-1 yaitu 5 input data, 5 neuron pada hidden layer dan 1 output. Variabel input terdiri dari 5 yaitu berupa data rata-rata kecepatan angin pada hari sebelumnya (xt-1, xt-2, xt-3, xt4), data rata-rata kecepatan pada angin hari sekarang (xt). Hasil pengujian dibandingkan dengan data akurasi dapat dilihat pada tabel 3 . 
TABEL III

HASIL PENGUJIAN DATA TARGET DAN DATA PENGUJIAN

\begin{tabular}{|c|c|c|c|c|c|c|c|}
\hline \multirow{2}{*}{ No } & & \multicolumn{4}{|c|}{ Input } & \multicolumn{2}{c|}{ Output } \\
\cline { 2 - 8 } & $\begin{array}{c}\text { xt- } \\
4\end{array}$ & $\begin{array}{c}\text { xt- } \\
3\end{array}$ & $\begin{array}{c}\text { xt- } \\
2\end{array}$ & $\begin{array}{c}\text { xt- } \\
1\end{array}$ & xt & $\begin{array}{c}\text { Target } \\
(\mathrm{xt}+1)\end{array}$ & Testing \\
\hline 1 & 6 & 5 & 5 & 5 & 5 & 6 & 4,79 \\
\hline 2 & 5 & 5 & 5 & 5 & 6 & 5 & 4,91 \\
\hline 3 & 5 & 5 & 5 & 6 & 5 & 7 & 4,75 \\
\hline$\ldots$ & & $\ldots$ & $\ldots$ & $\ldots$ & $\ldots$ & $\ldots$ & $\ldots$ \\
\hline$\ldots$ & & $\ldots$ & $\ldots$ & $\ldots$ & $\ldots$ & $\ldots$ & $\ldots$ \\
\hline$\ldots$ & & $\ldots$ & $\ldots$ & $\ldots$ & $\ldots$ & $\ldots$ & $\ldots$ \\
\hline 52 & 6 & 6 & 4 & 4 & 4 & 5 & 5,48 \\
\hline 53 & 6 & 4 & 4 & 4 & 5 & 8 & 5,18 \\
\hline 54 & 4 & 4 & 4 & 5 & 8 & 4 & 5,87 \\
\hline
\end{tabular}

Perbandingan hasil prediksi RBFNN dapat dilihat pada gambar berikut :

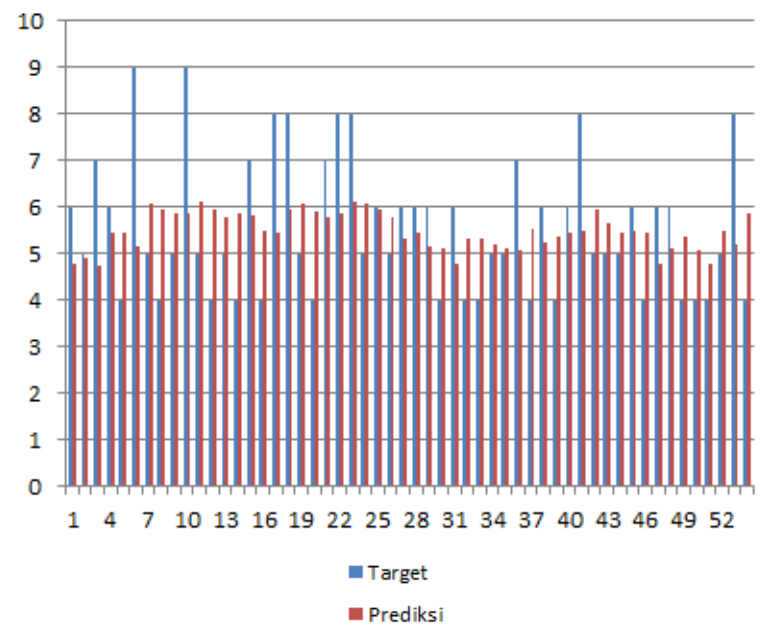

Gambar 7. Perbandingan Hasil Data Hasil Prediksi dan Data Asli (Target) Menggunakan RBFNN

\section{Akurasi Prediksi ANFIS dan RFNN}

Dari kedua hasil prediksi ANFIS dan RBFNN dibandingan dengan data asli, hasil perbandingan dapat dilihat dari tabel 4 dan gambar 8. Nilai RMSE kedua metode dapat dilihat pada tabel 5

TABEL IV

HASIL PERBANDINGAN PREDIKSI ANFIS DENGAN RBFNN DENGAN TARGET

\begin{tabular}{|c|c|c|c|}
\hline No & ANFIS & RBFNN & Target \\
\hline 1 & 5.58 & 5.65 & 5 \\
\hline 2 & 5.51 & 5.58 & 7 \\
\hline 3 & 5.47 & 5.51 & 6 \\
\hline$\ldots$ & $\ldots$ & $\ldots$ & $\ldots$ \\
\hline$\ldots$ & $\ldots$ & $\ldots$ & $\ldots$ \\
\hline$\ldots$ & $\ldots$ & $\ldots$ & $\ldots$ \\
\hline 52 & 6.2648 & 6.16 & 5 \\
\hline 53 & 6.0199 & 6.26 & 8 \\
\hline 54 & 5.1647 & 6.02 & 4 \\
\hline
\end{tabular}

TABEL V

Perbandingan Nilai Rata-Rata RMSE ANFIS dan RBFNN

\begin{tabular}{|c|c|}
\hline ANFIS & 1,1456 \\
\hline RBF & 0,1766 \\
\hline
\end{tabular}

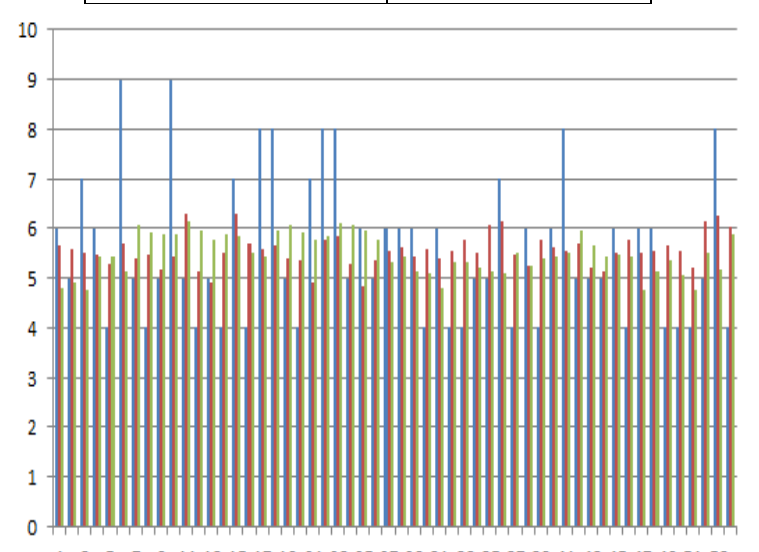

1357911131517192123252729313335373941434547495153

$$
\begin{aligned}
& \text { - Target } \\
& \text { - Prediksi AN FIS } \\
& \text { — Prediksi RBFN N }
\end{aligned}
$$

Gambar 8. Perbandingan Hasil Data Hasil Prediksi dan Data Asli (Target) Menggunakan RBFNN

\section{KESIMPULAN}

Perbandingan nilai RMSE antara ANFIS dan RBFNN menggunakan 54 data uji menunjukkan bahwa tingkat error terendah diperoleh dengan metode RBFNN yaitu 0,1766 sedangkan RMSE ANFIS adalah 1,1456, hal ini menunjukkan bahwa metode RBFF lebih baik dari pada ANFIS untuk prediksi kecepatan angin.

\section{REFERENSI}

[1] Putri. A, Syafriadi. Y, and Mustakim, "Analisa Pengaruh Temperatur Terhadap Titik Embun, Jarak Pandang, Kecepatan Angin, dan Curah Hujan Metode Regresi Linier Berganda," Seminar Nasional Teknologi Informasi, Komunikasi dan Industri (SNTIKI) 9, pp. 227-234, 2017.

[2] Hilmansyah,Yuniar. R. J, and Ramli, "Pemodelan Pembangkit Listrik Tenaga Angin Menggunakan Kendali Pi," Jurnal Sains Terapan, vol 1, no.3, pp. 22-26, 2017.

[3] Hakimi. F. D. D,.Anshori. M. N. A, and Asyhar. A. H, "Peramalan Kecepatan Angin yang Direkam oleh Sistem AWS dengan Analisis Fuzzy Time Series," Jurnal Kubik vol 2, pp. 2432, 2017.

[4] Dewi. C and Himawati, "Prediksi Tingkat Pengangguran Menggunakan Adaptif Neuro Fuzzy Inference System (ANFIS)," Konferensi Nasional Sistem \& Informatika 2015, pp. 228 -231, 2017.

[5] Kalaiselvi. C. M and Nasira. G. M, "A New Approach for Diagnosis of Diabetes and Prediction of Cancer Using ANFIS," 2014 World Congress on Computing and Communication Technologies, pp. 188-190, 2014.

[6] Althaer A and Barukab O, "Andorid Malware Classification Based on ANFIS with Fuzzy C-Means Clustering Using Significant Application Permissions," Turkish Journal of Electrical Engineering \& Computer Sciences, vol. 25, pp. 2232 2242, 2017.

[7] Svalina.I, Galiza. V, Lujic. R and Simunovic. G, " An Adaptive Network-Based Fuzzy Inference System (ANFIS) for The Forecasting : The Case of Close Price Indices, :Expert System With Application, vol 40, no.15, pp. 6055-6063, 2013. 
[8] Rout. A. K and Dash. P. K, “Forecasting Foreign Exchange Rate Using Hybrid Functional Link RBF Neural Network and Lavemberg-Marquardt Learning Algorithm, "Intelligence Decision Technology Journal ,vol 10, no . 3, pp. 299-313, 2016.

[9] Santoso. S, Widjanarko. A, and Supriyanto. C, "Model Prediksi Penyakit Ginjal Kronik Menggunakan Radial Basis Function, "Jurnal Pseudocode, vol. 3, no. 2), pp. 163-170, 2016.
[10] Chang. W, "Short-Term Load Forecasting Using Radial Basis Function Neural Network, "Journal of Computer and Communications 3, pp. 40-45, 2015.

[11] Stewart R. H, "Introduction To Physical Oceanography., "Texas: Department of Oceanography Texas A \& M University, 2018.

[12] T. Chai and R. R Draxler, “ Root Mean Squared Error (RMSE) or Mean Absolute Error (MAE) ? -Arguments againts avoiding RMSE in the literature,"Geosci Model Dev., 7, pp. 1247-1250, 2014. 